\title{
GUGUR GEGER NUSANTARA \\ DILIHAT DARI PERSPEKTIF ILMU SEJARAH
}

\author{
I Made Pageh ${ }^{1}$ \\ Universitas Pendidikan Ganesha
}

\section{Identitas Buku}

Semoga saya tidak salah menilai,--"menilai bunga mawar dengan ukuran bunga melati"--, yaitu menilai karya non-sejarah dengan ilmu sejarah.Namun secara verbal segala bentuk peristiwa masa lalu adalah sejarah. Karya Iwan Pranajaya dan Surya Majapahit (IS), adalah goresan karya kreatif "bercitra pembenaran sejarah menurut IS yang selama ini dianggap paling benar oleh umum". Karya Iwan Pranajaya dan Surya Majapahit (IS): Medang I Bumi Mataram Gerbang Kerajaan Majapahit: Geger Nusantara", merupakan karya yang mengegerkan nusantara, sehingga sangat menarik untuk dibedah.

Buku ini diterbitkan oleh tim Surya Majapahit, di Denpasar tahun 2017 (setebal 151 hal. termasuk lampiran). Buku ini diantar oleh dua tokoh: (1) Tokoh ketua PHDI dan Rektor IHDN Denpasar Prof. Dr. Drs. I Gusti Ngurah Sudiana, M.Si., disebutkan bahwa buku ini membahas mitologi hingga zaman Majapahit, dan membahas sejarah berbeda dengan teori sejarah umumnya, disinyalir akan dapat memberikan gambaran sejarah baru. (2) sejarawan lain, Prof. Dr. I Gde Parimartha, M.A. menyebutkan buku ini merupakan hasil karya anak muda kreatif, dengan sudut pandang dari Bali Utara.iwandkk mengidentikasi pusat kerajaan Majapahit ada di Bungkulan, dan tokohtokoh besar sejarah Indonesia lama sebagian besar kawitannya di Bungkulan.

Secara metodologis, buku inimenggunakan epistemologi mencari kebenaran dengan metode "anumana pramana" (pandangan tradisional). Disarakan memperkuat analisis dengan semiotika, yaitu ilmu tentang tanda (cf. Recouer, 2008; Sumaryono, 1999; Palmer, 2005; Tinarbuko, 2009), karena kurang alat analisisnya maka dapat menggambarkan cerita sejarah yang berbeda dari karya sejarah akademik umumnya (Parimartha, 2017: iv-v). pemaparan diakhiri dengan harapan terus berkarya dan dijadikan teman diskusi sampai kebenaran yang diinginkan oleh Iwan, dkk. dapat ditemukan.

\footnotetext{
${ }^{1}$ Tulisanini dikerjakan dalam rangka Bedah Buku Iwan Prabajaya dan Surya Majapahit, 2017. Medang I Bumi Mataram Gerbang Kerajaan Majapahit: Geger Nusantara. Xeanz Publisher: Denpasar. Tanggal 21 April 2018 di Kampus FHIS Undiksha Singaraja Bali.
} 
Teori dan Kerangka Berpikir

Tidak ada kebenaran tunggal dalam membahas sejarah, karena kebenaran sangat ditentukan oleh perspektif, teori, filosofi, personal, dan kepentingan penulisannya. Meskipun sumber yang digunakan sama, dapat menghasilkan makna dan cerita sejarah yang berbeda. IImu pengetahuan membutuhkan dasar rasional secara sistematis, ajeg, dan dapat dipertanggungjawabkan dalam disiplin yang ditawarkan oleh penulisnya.

1. Beberapa Konsep Ilmu Sejarah

Beberapa konsep fungsional untuk menyatukan persepsi tentang masa lalu di antaranya.

a. Sejarah adalah ilmu tentang urut peristiwa dalam waktu, periodisasi, dan peristiwa.

b. Peristiwa dalam konteks ini adalah "pemolaan", pembangunan pura, relief, pematungannya,tataletaknya, dsb.

c. Teori adalah sebuah hubungan/korelasi dari beberapa konsep membentuk sebuah pemahaman, yang memiliki perspektif, dasar, asumsi, dan persepsi-persepsi, yang menjadi isi kepala peneliti.

d. Teori yang patut dijadikan pandangan bekal mengkaji sejarah, misalnya: Teori Strukturasi Giddens (2010), memberikan pemakahan bahwa : "Waktu-Agensi-Struktur" memiliki keterikatan satu dengan yang lainnya secara simultan. e. Waktu berjalan secara kontinuitas tanpa henti, sehingga dalam belajar sejarah perlu periodisasi, setiap zaman memiliki "zeitgeist dan cultuurgebudenheid", jiwa zaman dan ikatan budaya zaman yang melingkupinya. Altussers (2014) menyebut jiwa zaman sebagai ideologi yang menrarahkan, membawa, menjadikan, mempengaruhi tindakan manusia, sebagai tatanam mental yang mengontrol tindakan manusia.

f. Agensi bisa berupa tatanan negara, kelompok, personal (relasi kuasa) yang memiliki budaya untuk dipolakan dalam masyarakat. Struktur adalah pola budaya, politik, social, kehidupan masyarakat yang menjadi trend umum.

g. Konsep Perubahan : Pro- ke Post, konsep dikembangkan oleh Homi Bhabha, yaitu konsep "Mimikri dan Hibridasi" (cf. Martono, 2014).

h. Teori Strukturasi: ${ }^{2}$

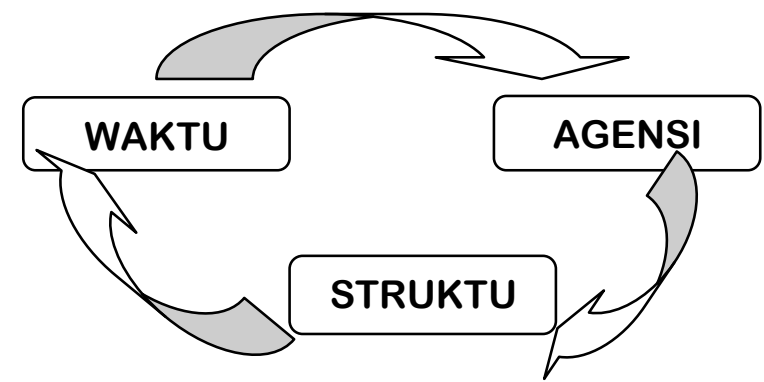

\footnotetext{
${ }^{2}$ Teori lain yang perlu dipertimbangkan adalah teori Relasi kuasanya M. Foucault, teori Hegemoni dan Dominasinya Gramsci, Teori Orientalisnya Edward Said, dll.
} 
i. Kerangka Berpikir Historis, dengan teori Strukturasi: Waktu, Agen, dan Struktur



Keterangan:

1. Tife M.A (Megalitik, Asli). Zaman prasejarah (Megalithicum): Kayu besar, Menhir, Funden Berundak, Sarkopagus, dll. Dengan Cultus Bhatara sebagai Leluhur (Pelindung).

2. Tife S-2 (Struktur 2/Rwabhineda). Ideologi Rsi Markandeya, masuk abad ke-8 (dari Gn Raung Jatim), Bali Aga. Ppemaduan Lokal Genius pemujaan Leluhur dengan Hinduisme, Cultus Dewa Raja.

3. Tife-S-3 (Trimurti). Ideologi Kuturan $^{3}$ (zaman raja Udayana dan Mahendradatta, abad 12) Pemolaan zaman Jaya Pangus dengan manunggalkan BhudaHindu. Cultus Dewa Raja berlanjut, dengan pembangunan Meru legitimasinya.

4. Ideologi Danghyang Nirartha, Ciwa Sidanta. Cultus Rsi Dewa, dominasi penunggalan couter ideology dengan Islam di Jawa.

Inilah konsep, teori, dan kerangka berpikir yang saya gunakan untuk menilai karya IS, dilihat dari

\footnotetext{
${ }^{3}$ Tiga tokoh ini dapat disebut Cultural heroes yang banyak mempengaruhi ideology (pemolaan) dalam sistem religi di Bali, tentu harus diingat ada zaman batu Besar (Megalithicum) yang besar kontribusinya terhadap sistem religi di Bali.
}

perspektif ilmu sejarah. Sekali lagi saya tegaskan perbedaan ini akan menghasilkan pemahaman dan kebenaran yang berbeda. Pilihan ada pada pembaca untuk memilih, namun secara akademik karena karya ini mengklaim kebenaran sejarah, maka akandijelaskan objek yang sama dengan pendekatan sejarah ilmiah. Pemahaman kebenarannya bisa sama dan bisa pula berbeda, yang jelas tidak ada kebenaran tunggal dalam sebuah cerita masa lalu.

\section{KaryaGegerNusantara}

$\begin{array}{clcr}\text { Bali } & \text { Utara secara umum } \\ \text { merupakan } & \text { daerah yang menjadi }\end{array}$ gerbang utama masuknya pengaruh luar, terutama zaman Bali Kuno-Bali Pertengahan, sebelum masuknya bangsa Barat ke Bali. Alasan pertama peninggalan sejarah, berupa artefak, tulang/fosil ditemukan dari daerah Cekik- Pacung di Timur (sudah eksis sekitar 250 tahun SM); kedua manusia masih dideterminasi oleh alam, daerah Indonesia dalam ombaknya, anginnya, gelombang samudra memungkinkan berlayar dengan perahu di Bali Utara; (3) banyak bukti awal pengaruh hinduisme ditemukan di Bali Utara, termasuk di Bungkulan. Sampai di sini pandangan IS sangat memungkinkan. Bahkan memang benar bahwa penemuan situs Bhuda di Kalibukbuk (Hotel Angsoka), dan Kalang Anyar mengugurkan teori sejarawan barat mengatakan Hinduisme itu bermula dari Bali Selatan (Balnjong Sanur dan atau daerah Pejeng Gianyar. 
Kata Bungkulan menurut pandangan saya memang lebih cocok dicarikan toponimnya (kesamaan namanya) dengan "Bengkulen" (menjadi Bungkulen), wilayah yang ada di Sumatra Selatan, daerah pusat perdagangan di daerah Barat Jawa.Daerah yang kuat kena pengaruh Budha/Sriwijaya yang menjadi saingan kuat raja-raja Jawa Timur (Raja WuraWari disinyalir penyebab pralaya Kediri dari Swarna Dwipa). (Karya Iwan Pranajaya dan Surya Majapahit, "Medang I Bumi Mataram Gerbang Kerajaan Majapahit: Geger Nusantara: Geger Nusantara"(Denpasar, 2017, total 161 halaman).

[---“IS menyebutkan daerah Bungkulan Gigir Manuk (punggung Ayam), titik nol, merupakan kawitan trah raja-raja nusantara atau trah dalem, serta kawitan dari raja Siliwangi (Pejajaran). Keduanya berdampingan dalam satu lokasi. Ada di Pura Dalm Kresna Kepakisan, di pura ini ditemukan "Stempel Otentik Kerajaan, terpenting stempel Surya Majapahit, terbuat dari kayu, ditemukan pula tokoh-tokoh besar seperti Gajah Mada, Kebo Iwa, dn diidentifikasi daerah ini sebagai "pusat pemerintahan Majapahit". Detail lainnya terkait dengan Gajah Mada, sosok tunggal dengan Prabu Udayana (bedanya dalam kedudukan Patih dan /Raja). Kebo Iwa (bergelar Sri Tabanendra Warmadewa) berkedudukan sebagai raja di Tabanan, dengan pusat Pura Batukaru (disamakan dengan Sri Masula-Masuli), kembar buncing'(lihat halaman 11). Identifikasi Perang Bubat Bungkulan tempat Gajah Mada, Tribhuana, dan Ayam Wuruk menunggu Dyah Pitaloka putriPrabu Lingga Buana, berlabuh dipantai Lingga(hal. 13-16; ), perlambang yang digunakan sebagai sumber ilustrasi adalah Lukisan Wayang Kamasan (hal. 17-38)---.

--- IS menggunakan literatur Keraton Sawangan (dari sawanganbali. http://blogspot.co.id/p/pe) menyebut sungai Jimba, diidentifikasi Tukad Yeh Aya, juga terkait dengan warna merahputih diambil dari "tanah Barat ada di desa Seraya Karangasem, dan tanah putih di HBB, menjadi panji merah-putih di Majapahit,-Udayana (Sri Dharmodayana Marakata Pangkajastano Tunggadewa) dibalikan menjadi "market atep pengkaje" , diarahkannya ke daerah Bungkulan. Sistem trah yang ada di Bali untuk mewariskan ketrampilan khusus dari leluhurnya, agar tetap ajeg keahliannya. Ngelong trah (kamuplase/nyineb pusat kerajaan) di Bungkulan, untuk menghinari kehancuran pusat kerajaan yang ada di Gelgel dan di Majapahit.-dst.... $]^{4}$

Secara kronologis karya IS banyak yang menyimpang dari penggalan waktu, dalam sejarah akademik.Seperti disebutkan dalam teori kronologis, setiap zaman akan memiliki jiwa dan budaya zaman yang berbeda, dan kontinuitas dan diskontinuitas dari ideologi masa sebelumnya, dapat dipahami dengan teori perubahan yang disebut mimikri dan atau hibridasi. Paling tidak dalam abad, kalau tidak dapat menunjukkan waktunya secara pasti.

Sejarah sebagai ilmu yang penting ada heuristic, kritik, interpretasi, dan penulisan (simpulan putusan

\footnotetext{
${ }^{4}$ Hasil pembacaan karya IS (buku yang dibedah).
} 
penulis dalam bentuk eksplanasi secara kronologis). Cerita,penjelasan fakta, dan hubungan sebab akibat, dengan memperhatikan prinsip koligasi (pembabakan, kesesuaian zaman) dibuat dalam bentuk pemahaman rasional, sistematis, terbuktikan bahan ceritanya.

Kesalahan kronologis berakibat fatal terhadap pemahaman (verstehen), karena hibridasi dan mimikrinya tidak dapat dijelaskan, dalam karya IS. Tidak ada sesuatu di dunia ini tanpa genealogi, hampir semuanya dapat dijelaskan, secara realitas, kecuali kepercayaan yang didasari oleh dogmatis, mitis, atau karena tidak ada sumber atau pengetahuan padanya, yang benar-benar baru sebagai invention. Berikut akan dijelaskan beberapa poin yang perlu IS klarifikasi, terutama fakta yang mengegerkan nusantara.

\section{Kegagalan Konstruksi Fakta}

Beberapa fakta bertentangan dengan bukti kuat peristiwa sejarah terkait dengan Bali, khususnya Bali Utara.

1. Analisis (where/Locus/field), disinyalir IS sebagai pusat pemerintahan Majapahit (lihat hal.6). Pembuktian berpikir Tife S2: Pura segara dicari Pura Gunungnya, dan atau Pura Gunung Sarinya (terbuktikan ada); Penandanya Batu Tapak dua Kaki dikerjakan oleh Kebo Iwa, simbol kekuasaan raja Waisnawa (pengikut ideologi, pemolaan (IS), "seterelisasi prasasti Ciaruteum Bogor (Bali=Banten) ,.... Inilah telapak kaki yang mulia Sang Purnawarman menguasai dunia sebagai telapak Wisnu" (wujud kultus Dewa Raja); Pura Agung Bungkulan di damping Pande (pagu Tife S-3 cf Batur),sebagaiRaja lokalnya dengan Pura Dalem Purwa (Purwa=Muka+penguasa) (terbuktikan ada); Penandanya Pura Batur (tife S-3). Pasek/Pacek/Hamengku Bumi/Bwana di Jawa. Sistem kekuasaan sistem Banwa (maka penyisirannya ke dsa di atasnya, yaitu Menyali--- (banwa Menyali, Galungan, Sekumpul, dan Lemukih), daerah pantainya berkembang sistem kekuasaan pakraman baru, sama dengan pola kubutambahan (tife S-2 dan S-3). ${ }^{5}$

2. Zaman Raja Jaya Pangus, gugur bermasalah sistem kultus dewa rajanya, karena raja memiliki istri seorang Budha bernama Kang Ceng Wie (ayahnya bernama Ping-An, saudagar pinggan berlokasi di Pura Pegonjongan/Gretek dan membuat lokasi pengepulnya di Pingggan Kintamani (Desa Pinggan), sehingga rakyat menolak kuasa rajanya, dengan alasan melanggar kultus dewa raja itu, dan anaknya yang buncing bernama "Ma-Sula dan Ma- Suli/ warga Ma di

\footnotetext{
${ }^{5}$ Banwasama dengan gebog domas, di dalam banwa itu ada raja-lokal-dan dukuhnya/rsinya di masa zaman Bali kuno awal. Di Pura desa distanakah roh leluhur semua klan, raja sebagai puncaknya, dibuat meru berjejer yang paling tinggi posisi raja. Pura banwa/Pura Desa dilengkapi Balai Agung Kembar, lokus posisi ulu apad dalam tife S-2 yang sama fungsinya dengan Balai Banjar setelah Zaman Kuturan (Tife-S-3). Sedangkan Jagaraga adalah sistem banjar baru, setelah abad ke-19 (menjelang pembangunan Benteng Jagaraga, setelah tahun 1846-1849.Palemahan itu milik banwa Menyali.
} 
Cina, Masora dan Masori di Besakih). Akibatnya, raja dan anaknya ditolak dan dianggap bukan turunan dewa atau dewa lagi. Untuk itu dan untuk membangun kepercayaan rakyat, dia mengeluarkan sekitar 40 prasasti, dan istrinya selalu disandingkan dan semuanya mengaku turunan Bulan (sekta Surya: "Bulan Matahari, bintang tarnggana"); Istrinya dijadikan Ratu Ayu Syah Bandar mengatur perdagangan laut; memposisikan diri dan istrinya sebagai BarongLandung menguatkan kedudukannya sebagai Dewa Pelindung; Mempolakan pura di Bali dalam penanda Hindu dan Budha, berbentuk hibridasi; Penanda/perlambangnya menjadi makhluk-makhluk serem, seperti: Harimau, Singa, Gajah Mina, Mina Warak, dan sebagainya.

CeritaBubuksah dan Gagak aking dengan turunnya Raja Hutan direliefkan dalam bentuk cerita Ciwa Bhuda turun ke dunia dalam wujud Singa, Harimau pada relief Candi Sukuh Jatim. Terjadi "dominasi, hegemon, mimikri, dan hibridasi", antara Waisnawa, Trimurti, Bhuda Mahayana, dan Ciwaisme dalam perjalanan sistem religi di Bali. Contoh: Singaraja--- Hindu Waisnawa dan Bhuda-Sayapnya Garuda kendaraan Wisnu, dan Singa wujud Bhuda Mahayana; Gajah-Mina: hibridasi Ganapati-Waisnawa; Wilmana manusia bersayap (Bhuda-Wisnu); sedangkan wujud randa sudah jelas sekta Ciwa perlambang

Sedangkan

Rangdeng

Banaspati raja) Sang Catur Sanak manusia sakti, simbolisasinya terdapat dalam tari Barong, Rangda dengan sisyanya melawan Barong dengan Bojog Hitamnya (sekta Waisnawanya), sehingga dalam perang sekta itu hasilnya drow (sapih sama kuat). Ini adalah analisis simbolik, karena simbolik atau perlambang maka bersifat dinamis dan multitafsir, sangat bergantung pada "Waktu-tempatagansi- dan struktur masyarakatnya" (Giddens, 2010). Salah memegal waktu, agen, dan struktur maka akan berakibat menjadi uraian tanpa konteks (menjadi sebuah keyakinan tanpa kronologis/ilmu sejarah).

Dengan demikian saya menafsirkan pelinggih Sri Kresna Kepakisan di Bungkulan, yang disinyalir "Kawitan Raja-raja dan Patih besar Nusantara": (1) merupakan bentuk hibridasi yang awalnya bentuk pelinggih tipe S-3; (2) kemudian di tahun 1927-an terjadi renovasi pelinggih di Bali Utara zaman Baliseering ajeg Bali zaman Belanda, sehingga dalam rehab itu, masuklah ideologi Ciwaisme ikut berhibridasi di dalamnya (zeitgeist dan cultuurgebudenheid) dalam periodisasi, sehingga menjadi tipe $\mathrm{F}-\mathrm{H}$ (Fertilitas Hybrid).

Analisis situs palinggih yang didata IS di Bungkulan memiliki sebaran sign/tanda-tanda/simbol/perlambang gambaran tipe M.A, TipeS-2, tipe S-3, tipe F.H. Pura Kawitan Sri Kresna Kepakisan diklaim sebagai pusat pemerintahan dan pusat genealogi rajaraja dan tokoh-tokoh besar Nusantara Kepakisan yang memerintah tahun 
1350-1373 M. Memiliki ciri-ciri zaman Jaya Pangus, saya lebih menafsir pelinggih abad ke-12 direnovasi kemudian menjadi tambahan ciri-ciri hibridasi tipe S-9 dan Tipe F.H.

Relief dan Babad merupakan sumber sejarah paling lemah, karena penuh dengan "konstruksi politik/relasi kuasa/pendewaan siempunya Babad).Dengan demikian untukmendapat patokan abad paling tidak perlu pembacaan sumber sejarah lebih valid dan mendalam, dan yang sezaman seperti prasasti (tambra sasti).Yang banyak ditemukan di Bali Utara adalah prasasti yang dikeluarkan oleh Jaya Pangus (1099-1103).

"Saya menjadi ragu setelah membaca Prasasti Ragajaya, dibuat Jaya Pangus bertahun 1155 Masehi: menyebut desa Les, Paminggir (hiliran/Tejakula), Buhundalem, Julah, Purwasidi, indrapura,Bulihan,Manasa,Banyubrah , Manasa, bukit sinunggal (cf Prasasti Raja Ekajaya Lencana); P. Sembiran 975 Masehi, hampir sama isinya dengan Prasasti Julah, prasasti Bebetin, dan Prasasti Kerobokan/ Sanding Bulian Tamblingan, Prasasti Gobleg, Prasasti Banyusri. Tidak ada menyebut Pura itu, dan tidak ada disebut-sebut Bungkulan atau"Bengkulen", di Bungkulan. Yang banyak disebut-sebut justru Hiliran, Bulihan, Manasa, Banyubrah, Tamblingan, Bantiran, dan Desa Wintang Ranu (Bintang Danu), buahan, trunyan, abang, maniklyu, lantih, panarajon/pucak penulisan."

\footnotetext{
${ }^{6}$ Purwasidi seharusnya terletak antara JulahDepaha tidak diidentifikasi sekarang, oleh Ginarsa.Tejakula berasal dari kuula-kuula (u dirge) yang berarti tepi/pinggir, ditambah mitos
}

3. Alasan sayan, penanda tipe S-2 dan S-3 lainnya adalah Pura Dalem Balingkang, itu adalah tipe S-3, dapat dipastikan akan ada Ratu Ayu Syahbandarnya, Dalem Pingitnya, penanda Kudanya (dagang), penanda Harimaunya. Memposisikan Kang Ceng Wie sebagai Dewi seperti Dewi Danu (istri pertamanya) di daerah Songan Batur (tife S-2). Sedangkan Pura Batur di Banuwa Batur, masuk tipe S-3 dan kini didominasi dengan tipe $\mathrm{F}-\mathrm{H}$ (mimikri Siwa). Penandanya meru berjejer, dan ada pelinggih untuk Syahbandarnya (cf. Puru Batur); Pura Jati (PasekKayu Selem) (tipe S-2); dan penanda relief yang diperlihatkan dalam Buku IS Geger Nusantara.

4. Pemerintahan Ketut Ngulesir di Gelgel (1380-1460 M), kakaknya bernama Agra Samprangan (lemah), dan Dalem Tarukan (suka Kekayaan diPula Sari), Putri (tidak jelas namanya), dan Dalem Ketut Ngulesir dijadikan raja di Gelgel. Representasinya adalah Pura Dalem Ketut (ada tipe S-9 dan tipe F.H); Pura Dalem Puri; Pura Kentel Gumi; Pamrajan Satria; Gelgel merupakan raja yang digadang oleh Arya Kloping (sama dengan Arya Kelapadiana, A. Kebon Tubuh, A. Batan Nyuh) yang merelakan tanahnya sebagai Puri Gelgel, sehingga dia dibawa ke Gelgel dari

\footnotetext{
teja kukus (sinar melejeg ke langit) menjadi kini menjadi Tejakula.
} 
Pandak Gede Tabanan.

Penandanya Pura Batan Nyuh.

5. Zaman pemerintahan Agra Samprangan banyak terjadi pembrontakan desa Bali Aga, karena tidak sepenuhnya mengakui raja Dalem sebagai Titisan Wisnu dari Airlangga/ Daha dan Kediri), dia dari faksiBlambangan, dan turunan seorang Brahmana. Hal ini diasumsikan sebagai "Enceh Gumi Baline", sehingga muncul "Pura Kentel Gumi dan Setra Ganda Mayu" (ada di Bungkulan), serta wujud pura tiga Klan yaitu Pande (Brahma, Rsi, Raja),konsepNgaben Massal setelah Perang Brata Yuda (sesuluh dari EfosMahabratha). BelumMuncul Brahmana yang mendominasi sampai Kultus Resi Dewa (Dewa Brahma+ana, Ciwa ia, Surya ia, Pedanda ia, Guru ia, Bagus ia). ${ }^{7}$

Analisis Foto, Patung, Relief.

Bagaimana seharusnya dijelaskan beberapa perlambang pada pura yang dijadikan "geger nusantara ini", contoh penggunaan teori yang saya ajukan, agar dapat mengerti apa sesungguhnya dilambangkan, ideologi apa yang tersembunyi di baliknya, apa yang mimikri dan atau berhibridasi di dalamnya.

\footnotetext{
${ }^{7} \mathrm{Hal}$ ini konstruksi zaman Baliseering zaman kolonial (indirect rule) kolonial Belanda di Bali, raja jadi regent zaman kolonial, hegemoni terakhir kolonial Belanda, menyiapkan pura-pura di Bali Utara menjadi objek pariwisata menarik dan ritual eksotis.
}

(1) Rentetan Meru pada halaman 46, harus dipahami dalam tipe $\mathrm{S}-3$ zaman Jaya Pangus berubah ke dominasi Gelgel setelah kekuasaan Dalem Kresna Kepakisan.

(2) Foto hal 49 berbentuk Budhaisme Mahayana (Harimau) raja hutan bercitra Ciwaisme.

(3) Foto-foto hal 52, tipe S-9 Ciwaistik di tengah, hibridasi sektarian (Tife S-2) dan Budha Mahayana.

(4) Foto -foto Pura Dalem Balingkang: mistik dengan penanda kultus dewa raja, Kuda dan babi Hitam (Budha dan Wisnu) Kang Ceng Wie (Ratu Ayu Syahbandar) dan Jaya Pangus (Dalem Pingit). Sama dengan Gambur Ngalayang, ada Ratu Mekah, Sundawan, ratu Melayu, Dlaem Pingit, dan Dewa Tirta. Surya penunjuknya, sebagai sistem religi tipe S-3.

(5) Halaman 59 Syair Kidung tua: bermakna pertemuan dengan Islam, di bawah raja Batur (Jaya Pangus), peranakan Cina (ratu Syahbandar), Juru Kemudi pedagang berkemudi Kuda, Perahu, pedati, dll. Ciri-ciri dan penanda kekuasaan Jaya Pangus dengan Istrinya. Di Bungkulan, sama dengan pusat dagang di Sumatra Selatan Bengkulen.

(6) Foto halaman 63, Budhaisme (harimau) dengan Jaga Balanya.

(7) Foto-foto halaman 64: Dua Patok kaki (sama dengan simbol kaki raja, Waisnawa dalam kultus dewa raja) tipe S-2; di sampingnya ada 
simbol Surya (matahari) simbol sekta raja (Surya-Candra-Bintang Tranggana).

(8) Foto-foto hal. 73-74; Hibridasi Budha -Waisnawa, Budhanya ke Bairawa (Jaman Kebo Parud di Bali Singosari); Wayang berbendtuk Monyet adalah anak buah dari Sang Rama dan Sinta (Awatara Wisnu/ Waisnawa).

(9) Foto-foto halaman 77-78: Menjangan Seluang (tipe S-3), Harimau (Budhaisme), dua patok tipe S-2. Binatang yang dipegang pahami melalui mitologi/folklore rakyat setempat.

(10) Foto-foto hal. 79-80: Patung dengan phalus besar (Budha Bairawa,ingat Kebo Edan Gianyar); Budha, Ganapati (sektarian).

(11) Foto-foto hal. 81-82: kalamakara (Bomantaka), monyet Waisnawa; Matahari (simbol sekta raja, di sampingnya ada Ciwaisme dan Budhaisme.

(12) Foto-foto hal. 83-84: Kuda, Singaraja, dan manusia bertopi (Kling atau Melayu). Pelinggih tipe S-3, tiang dengan tiga cabang di atasnya Trimuti bersatu menjadi Agama Negara (Pesamuan Tiga Gianyar), tipe S-3.

(13) Foto-foto hal. 85-86. Di Pura Dalem Purwa. Rangda motif Ciwa Durga, Bhuda, Wisnu, dan Raja (Mimikri budaya Agama).

(14) Foto-foto hal.hal 105-106; Pura Patih, seorang patih Dalem Balingkang (Jaya Pangus), bersekta Wisnu-Bhuda. Naga Wisnu dan Harimau bawah Budhaisme.

(15) Foto-foto hal. 107, inti sektanya pura itu, Kalaulaki ditengah dua putrid di sampingnya itu penanda Jaya Pangus dengan dua istrinya, Jika patung wayang (kera) Waisnawa.

(16) Foto hal.201. Banuwa dengan sekta Wisnupenanda di Pura Dalem Solo desa Sedang Badung. Daerah Badung merupakan daerah yang didominasi oleh tipe S-3 (Padma Trilingga).

(17) Silsilah halaman 122 meragukan dilihat dari isi prasasti, sehingga membutuhkan pembuktian, bahwa Kresna Kepakisan yang dari Desa Pakis Jawa Timur memang berasal dari Bungkulan? Raja-raja zaman Bali Aga memang didominasi oleh sekta Budha dan Sekta Waisnawa, serta sekta lainnya yang menjadi aliran kepercayaan masing-masing personal (pribadi).

(18) Foto hal.128. adalah foto kala makara, boma, yang di dalamnya berisi Lingga merupakan Pura Segara dari Pucak Penulisan, dengan perutnya di Bedulu (Pura Penataran Sasih dan Pura Pancering Jagat. Termasuk sistem religi tipe S-2, Nyegara-Gunung di tengah-tengah perutnya (pusar kehidupan), dengan sekta Surya Candra ranggana (Wisnawa, dengan Jaya Pangus sebagai Barong-Landung), berkedudukan di Bata Anyar, dan istri Bhudanya 
di Dalem Balingkang. Sejak itu kerajaan berkaki dua, yaitu: di selatan Bali dan di Utara Bali. Tetap tipe S-2 dan S-3.

\section{Simpulan.}

Dari analisis situs Bungkulan dengankeberadaan Pura dengan namanama dan lokasipura dan penanda lainnya, dapat disimpulkan bahwa Gugur Geger Nusantara dilihat dari kaca mata ilmu sejarah, karena Situs Bungkulan masih dapat dijelaskan dengan konteks sejarah umumnya, yaitu terdiri dari dua tife utama yaitu tife S-2 dan S-3 yaitu sistem religi yang dikembangkan pengikut Rsi Markandeya abad ke -8 (tipe S-2), dan Tipe S-3 yang dikembangkan $\mathrm{Mpu}$ Kuturan abad ke-12. Dengan hibridasi Hindu-Budha ditampilkan dengan patung, relief, dan pemujaan raja sebagai dewa, karena ada relasi kuasa yang sangat kuat.Terutama pemolaan sistem religi yang ada sebelumnya berhibridasi dengan Trimurti, dan Raja Jaya Pangus dengan Istri Cinanya.

1. Kekuasaan di Bali Utara sebelum Ketut Ngulesir tidak berani ada mengusik Bali Utara karena masih ada dalam perlindungan pendiri Majapahit, yaitu Arya Wiraraja (penguasa di Madura zaman Singosari) yang dipersiapkan melawan KuBhilaikhan, dengan ekspedisi Pabalinya (1275 Masehi). Sehingga Budha Bairawa, dengan 5 Ma-nya dikembangkan, seperti Kebo Edan di Bedulu, wakilnya Raja Patih bernama Kebo Parud.

2. Kekuasaan Ketut Ngulesir melakukan dominasi ke Desa-desa Bali Aga, dengan mengirim penguasa lokal utusan Gelgel, juga terjadi dalam penguasaan daerah Bungkulan ini

3. Setempel Majapahit ternyata hanya sebagai simbol sekta raja ketika itu adalah Sekta SuryaCandra-Bintang Trangana, seperti pusat kekuasaannya di Bedulu (di bata Anyar dan Dalem Balingkang pada abad ke-12). Prasastiprasasti yang muncul di Bali Utara sebagian besar dikeluarkan oleh Raja Jaya Pangus dalam melegitimasi istrinya yang ditolak sebagai pendampingnya, karena seorang Budhis.

4. Raja Lingga Bhuana ketika dibaca dalam Blog yang ditunjuk hanyalah sebuah folkloreseperti Babad, yang mencoba melegitimasi klennya untuk dapat menjadi turunan raja lain trah, ketika terjadi peralihan kekuasaan.

5. Relief, patung, dan sistem religi terakhir ketika dikonstruksi setelah abad ke-16, banyak yang disesuaikan dengan konsep Siwa Tiga (Ciwa-Sada Ciwa, Parama Ciwa), yang sebelumnya BrahmaWisnu-Ciwa. Dan Rwabhinedanya diasosiasikan dengan tokoh leluhur, raja, resi.

6. Tidak dapat dibuktikan bahwa trah Kresna Kepakisan dari Bungkulan, dan adanya ajaran beliau melalui 
Ketut Ngulesir dan Arya Kloping adalah peristiwa politik yang terjadi pro dan kontra dalam menerima rajanya dari Pakis Jawa Timur, yang dibawa ke Bali oleh Gajah Mada, karena Gajah Mada berguru di Fakis itu, sehingga semua keluarganya menjadi bagian kekuasaan Gajahmada.

Saran-saran

(1) Perlu penelitian ini dilanjutkan dengan tidak hanya berdasarkan metode perlambang (semiotika saja) yang kalau dikontekskan dengan "waktu-agen-struktur" bisa menyesatkan, karena perlambang adalah bukti konstruksi zaman kemudian, yang didasari oleh hibridasi sistem religi, ideologi (zeitgeist), dan ikatan budaya jaman (Cultuurgebudenheid) ketika perlambang itu diciptakan.

(2) Disarankan untuk meneliti apakah mungkin cap surya Majapahit itu berumur sekitar 650 tahunan? Termasuk padas, dan relief yang dijadikan analisis perlambang. Sehingga perlu penguatan kritik sumber (eksternal dan internal), dan kemampuan koligasi, bukan hanya imajinasi seperti pengarang novel. Sejarah adalah cerita berfakta secara kronologis, sehingga maknanya ada dalamkonteks ideologi dan budaya zamannya.
(3) Perlu dilengkapi dengan pembacaan Prasasti Bulian, Bebetin, Goleg Pura Desa A dan $B$, Prasasti Raga Jaya (Teja Kula), dan Prasasi desa Julah, Sembiran, dan Prasasti Sanding Bulian Tamblingan yang merupakan gambaran tentang luasnya kekuasaan dan hegemoni Jaya Pangus bersama istrinya di Bali Utara dan Bali umumnya.

(4) Coba kaitkan Bungkulan dengan Banwa Menyali-Sekumpul, Galungan, dan Lemukih. Daerah pantai Bungkulan terkait dengan Nyegara-Gunungnya di masa lalu. Seperti daerah Kubutambahan terkait dengan Banwa Bulian-Depaha-Bayadtampekan/Tajum dengan Bukit Sinunggal sebagai hulunya.

\section{DaftarPustaka}

Atmodjo, R.M. Sukarto K. 1970. Manuskrip "Prasasti BuyanSanding-Tamblingan.

Disampaikan dalam Seminar Sejarah Nasional II, 26-29 Agustus di Yogyakarta.

Foucault, Michel. 2012. Arkeologi Pengetahuan. Inyak Ridwan Muzir (penerjemah). IRCiSoD: Yogyakarta.

Giddens, Anthony. 2010. Teori Strukturasi: Dasar-dasar Pembentukan Struktur Soaial Masyarakat. Pustaka Pelajar: Yogyakarta. 
Ginarsa, Ketut. tt. "Prasasti Baru Raja Ragajaya", dalam Majalah IImuilmu Sastra Indonesia.Maret Juni 1963. Jilid IV, No 1,2. UI: Jakarta.

Martono, Nanang. 2011. Sosiologi Perubahan Sosial: Perspektif Klasik, Modern, Postmodern, dan Postkolonial. Rajawali Pers: Jakarta.

Palmer, Richard E.Hermeneutika: Teori Baru Mengenai Interpretasi. Pustaka Pelajar: Yogyakarta.

Ricoeur, Paul.2009. Hermeneutika IImu Sosial. Kreasi Wacana: Yogyakarta.

Shastri, N.D. Pandit. 1963. Sejarah Bali Dwipa. Jilid I. Bhuwana Saraswati: Denpasar Bali.

Sumaryono, E. 2013. Hermeneutik: Sebuah Metode Filsafat. Kanisius: Yogyakarta.

Tinarbuko, Sumbo. 2009. Semiotika Komunikasi Visual. Jalasutra: Yogyakarta. 